\title{
Experiences of mentorship with academic staff doctoral candidates at a South African university
}

\author{
Anna Strebel and Tamara Shefer
}

\begin{abstract}
Given the growing emphasis on academic research output and the challenges encountered in expediting completion of doctoral studies especially, mentorship is increasingly being utilised as a capacity development strategy for supporting scholars to complete post-graduate studies. This article reports on a mentorship project aimed at academic staff enrolled for doctoral studies in a health sciences faculty at a South African university, based on reflections drawn from annual feedback from the mentees and the annual report of the mentor, as well as a focus group conducted with mentees by an independent researcher. Participants found the mentorship, with its combination of individual and group meetings, as well as regular residential writing retreats, to be extremely helpful. A number of key features that enable the mentorship process emerged, and issues relating to supervision and mentorship were highlighted, especially regarding power dynamics.
\end{abstract}

\section{Background}

There has been a growing acknowledgement globally and locally of the critical value of knowledge production for development. Within the South African context specifically, the understanding of higher education as a key driver for meeting the broader goals of socio-economic redress and transformation has been widely acknowledged (CHE/CREST 2009; Cloete and Bunting 2013; Pillay 2010). Moreover, the challenges of increasing specialised postgraduate output, especially at $\mathrm{PhD}$ and postdoctoral level, have also been foregrounded, given historical practices of exclusion and inadequate educational systems (Badat 2007; Mouton 2011).

South Africa continues to compare unfavourably to other countries with respect to doctoral output, producing a very small number of doctorates per million of the total population, together with lengthy time frames for graduation and high drop-out rates. In addition, doctoral graduates still reflect gender and race disparities, failing to represent adequately national demographics (ASSAf 2010; CHE/CREST 2009). Higher education institutions are in this context tasked with increasing postgraduate and scientific research output, with pressure to graduate more students across diverse areas (Badat 2007; Bitzer and Albertyn 2011; CHE/CREST 2009). This in turn highlights the requirement for academic staff to be effective supervisors within the context of these multiple pressures. 
This trend, together with the increasing diversity of the academic staff body, has necessitated a greater focus on more formal capacity development strategies among staff (Nundulall and Dorasamy 2012; Quinn and Vorster 2012; Schrubbe 2004). Informal mentorship or guidance of junior staff by more senior staff has long been an important component of many university academic and professional training departments. However, given the challenges and complexities of postgraduate supervision, the value of more formal academic mentorship as a key element within, or additional to, supervisory practices in higher educational institutions has been highlighted (Grant 2003; Kamler and Thomson, 2006; Louw and Muller 2014).

Thus, mentorship is increasingly being introduced as a practice for supporting emerging scholars in their research, whether at student or postdoctoral level (Clowes and Shefer 2013; Mullen, Fish and Hutinger 2010; Paglis, Green and Bauer 2006). The form that such mentorship takes varies within and across universities according to perceived needs, with peer mentorship and mentorship by more senior established academics of junior emerging staff being two of the current models (Geber 2010; Leidenfrost, Strassnig and Schutz 2014; Nundulall and Reddy 2011; Schulze 2010). However, there appears to be little documentation of the actual process and components of formal mentorship (Clutterbuck and Lane 2004; Eby, Rhodes and Allen 2007), as well as the relationship between mentorship and supervision.

In the light of such debates and practices, this article presents a descriptive case study of a mentorship project aimed at academic staff enrolled for doctoral studies in a health sciences faculty at a South African university. The initial aim of the project was to contribute to assisting senior staff to obtain the doctoral qualification, in order to strengthen research and supervision capacity in the units involved. The project has been underway for five years, starting with one mentor working with six mentees; the mentor currently has 10 participants, with another three having completed their theses and left the project. Notably both the mentor and all mentees so far are women. The programme has developed to include three main components. Firstly, the first author of this article, a senior, experienced researcher employed as an independent consultant, meets individually with mentees, either regularly or at the request of the mentee, depending on their needs and the phase of the research in which they are involved. These one-on-one sessions typically focus on topic identification or refinement; proposal development and preparation for presentation; support and inputs during the conducting of fieldwork; planning and implementation of analysis; feedback on drafts of sections of the thesis; time management; preparing manuscripts for publication and conference presentations; as well as general support and encouragement.

Secondly, the mentees meet with the mentor as a group on a monthly basis. Activities during this group meeting have varied over time, including presentations by individual mentees of the proposals they submit to faculty, or the current status of their work; presentations by the mentor or guest academics on aspects of research (e.g. the role of theory 
in research, conducting and analysing qualitative research); and annual evaluations of the project.

Thirdly, the mentor and mentees participate in regular three-day residential writing retreats, which take place at a venue away from the university and allow participants to work full-time on their research. Mentees work mainly individually, with group sessions as requested to report on their work and obtain feedback. They also consult with the mentor where there is a need.

\section{Methodology}

The current study reports on the experiences of mentees and the mentor involved in the mentorship project over the past five years. Reflections are drawn from annual verbal and written feedback from the mentees and the annual written report of the mentor, which are submitted to the university and the funders, as well as from a focus group conducted with mentees. Ethical approval for the research was obtained by the relevant committee in the university's health sciences faculty. For the focus group, a semi-structured interview guide was developed. The 10 mentees involved in the project at the time, who are all women academic staff members in the health sciences faculty of the university, agreed to participate, and signed informed consent forms. The focus group was conducted in English by an independent senior researcher, and audio-recorded. The session was transcribed verbatim and analysed thematically together with the annual reports, as presented below.

\section{Findings}

\section{Key components of the mentorship}

Participants identified features of the individual and group sessions, as well as the writing retreats, which they regarded as important for successful engagement in their studies.

\section{Individual sessions}

The one-on-one meetings between the mentor and individual mentees were regarded as central to mentorship as 'the foundation of the whole project', as articulated by one participant. These individual meetings were seen as an unthreatening, safe space, where candidates felt able to confront the challenges with which they were grappling:

I find it really helpful, uhm, as a safe space to deal with my insecurities because I think,... because I didn't feel like, I didn't feel like anyone was gonna judge me, or I didn't feel like [name of mentor] was gonna uhm you know, mind, so that was very helpful. [Participant 1]

This was seen as especially valuable within the context of the research-based PhD's relative isolation:

I think a PhD's such a lonely journey and I find ...I feel like this is the space, ... and when [mentor] asks, that's what she's there for, so you really, you know, you can talk about it in detail. So it becomes almost a contained space for ... ja, ... ja, for talking about it. It's just, it's 
as if, it seems, it can actually consume you, so I find it's a nice space to almost package it and say alright that's PhD time. [Participant 2]

In addition, participants valued the way in which these meetings allowed them to set goals, work toward deadlines, assist with time management and offered regular active follow up:

I needed to fix some timelines, I needed to work and have a couple of goals and get yourself moving and uhm, so I think it's quite a, ja, I think it was just at a particular point in my life that I needed. Without the mentorship, I really would not have progressed. Well, I would have, but a lot slower. [Participant 3]

They experienced the process of individual mentorship as a balance between support and challenge, which offered both motivation and encouragement:

But, but having, uhm, being able to plan things and having [mentor] to assist us to okay what's the next step and what are you gonna do and what are you gonna achieve by the next time and uhm, that bit of, there's the support and also the challenge, but in an encouraging way, it's not been, there hasn't been kind of any harshness around it if that's the right way to term it ... Ja ... setting those goals. [Participant 4]

\section{Group meetings}

Over time, the group meetings became a core feature of the mentorship. For most, these meetings were an important source of collegiality and support:

And also, just from having this group, you know, we all have such different lives, but we also have lots of points of connection ....and the relationship we have amongst each other and with each other. [Participant 3]

The group also provided invaluable opportunities to share ideas and obtain feedback, all of which helped to keep momentum going:

And having the opportunity to present to [mentor] ... ja ... and the group on different topics and that we can kind of practise, a couple of us have practised when we have to present the proposal to the, the school, and I had a kind of practice run and I was going to be presenting at a conference and like [mentee] was saying it's kind of a safe space, to do those kinds of things. [Participant 4]

\section{Writing retreats}

The experience of participants of the writing retreats was strongly positive, and was seen as a key component of successful mentorship. Feedback from both the mentees and the mentor was unanimous that these opportunities to get 'out of office' and focus solely on their thesis work were invaluable in providing consolidated work-time away from the usual hectic demands of academic work: 
It really is a treat to be able to spend two or three days of completely and utterly focused time on your research. It does not happen at any other time of the year, I don't think any of us ... ja ... would be able to put two or three days aside at any point and just focus on, on, on PhD work. [Participant 5]

This was experienced as especially helpful for those candidates who have to juggle the multiple roles of family and work:

I think one of the most beneficial things I think is that uh, so I've got a young family, so often it's really, really hard to get time away from everything else, from work and family. So these writing retreats are just amazing [giggles] / ja / to actually get time to work on my PhD. [Participant 6]

The retreats allowed the opportunity to connect with colleagues who grappled with similar issues, which over time has led to the development of a very supportive context, a 'community of colleagues', which provides solidarity and cohesion. Also, participants found the retreats to be energising, motivating and a boost to productivity:

These retreats allowed a level of productivity on my $\mathrm{PhD}$ that ordinarily, during a normal working week, is not possible. The concentrated time allocated just for research allows a level of focussing that results in greater levels of productivity in terms of the amount of work accomplished and idea-generation. In addition, the emotional and academic support provided by fellow [mentees] ensures continuous motivation. [Participant 5]

Another positive component of the retreats, according to participants, was the easy access to the mentor, for more formal discussions, but also for quick consultations, and feedback on written pieces of work.

From these findings, it would appear that a combination of individual and group interventions, together with periodic blocks of consolidated time away from the university in the form of writing retreats, provided an appropriate and effective mode of mentoring, as has been found at other local higher institutions and elsewhere (Geber and Bentley 2012; Govender and Dhunpath 2011; Mokone, Malema and Maphanga 2012; Noonan, Ballinger and Black 2007).

\section{Enabling features of the mentoring approach}

Feedback from the mentees also identified a number of features of the mentor's approach which appeared to be significant in facilitating the process of mentorship. A central consideration that mentees articulated was the fact that the mentor was located outside the faculty and departments, was 'unembedded', which allowed her to be regarded as unthreatening: 
And it was just really helpful to have somebody outside of the academic context to, as a sounding board to voice all my displeasure [giggles] and my, my anxiety about it. [Participant 7]

But I think it is important that this person is not involved in any sort of power dynamic with you. Your mentor cannot be your HOD or someone ... ja ... who's going to be invested, ja. [Participant 5]

Added to this, participants also articulated the way in which mentorship helped to deal with the feelings of insecurity and inadequacy which candidates often experienced:

But I think that one of the things that mentorship does for us is that, and one of the things that [mentor] has done for us is actually show that we are capable and we do have those knowledge and skills, and a right to say but I'm not sure about this, but then we find the things that we actually are sure about and that we can build on. [Participant 3]

Another factor that was identified was that not necessarily being involved directly in the particularity of the field of study of the doctoral work allowed the mentor to have a broader perspective on topics of investigation, to cast a 'fresh gaze' over work and to ask 'innocent' questions:

I think maybe some of the differences between the mentor and your supervisor is that your supervisor, for me certainly, my supervisor provides uhm, help in terms of the technical aspects of the study, uhm, whereas [mentor], uhm, kind of she does all of the rest of it, you know, which is actually a big part of it. So, all of those sort of, how're you progressing, where you're stuck, uhm, you know, how to negotiate that. Even as far as sort of, uhm, reading through, an outsider's perspective, reading through what I've written and saying okay, there's a nice flow of argument or, try and change something here, uhm, which I find very useful as well. [Participant 6]

A further factor was that mentees found the academic, research and life experience that this senior person brought to the process really helpful, as she had a good understanding of the challenges they faced. Thus, they valued the fact that the mentor was an established academic with extensive experience in higher education, as well as her credibility and professionalism:

She's got an understanding of how to be in an academic environment. And how to, how power works in that environment, what's important. And how to see a $\mathrm{PhD}$ in perspective, you know. So I think having that experience for a mentor is important. Also, kind of, [slight pause] I think, good interpersonal skills, whether it's humour or, being able to empathise or seeing where you're at, but also being uh, firm and supportive. [Participant 3] 
Another interesting feature of the mentoring approach was that it encouraged candidates to develop confidence in and ownership of their work, rather than relying solely on the suggestions of supervisors, or indeed the mentor:

Uhm, but there was one other thing which I thought was really important, uhm, she, [mentor]'s really emphasised our own ownership of the work, which I find really useful ... ja ... 'cause I thought my supervisor's sign-off was proof that it was good enough, uhm, whereas I feel like in the process of going through mentorship I feel I've realised that oh, ja, actually I need to be the one, that thinks this is, this is legitimate ... $\mathrm{mm}$... mm. [Participant 1]

A further factor that appeared to have an impact was that the mentor in this particular programme was also a clinical psychologist, and so was able also to pay attention to personal and contextual factors influencing mentees' work:

I think [mentor] having been a psychologist I think has helped [laughter] actually with this uhm, because part of that, you know, is there's no, you don't have to pretend. I mean, I've had dramas as I've gone along and actually they do impact you in your work. [Participant 7]

A final significant element that the mentees, all of whom were women, appreciated was that the mentor was also a woman, who could identify with the challenges they faced, and who thus also served as a role model:

... and I think what I found quite helpful was her own experiences. So she's a woman, she's had a family, she's walked the same career, uh, and got her PhD later on in her life. [Participant 3]

In addition, importantly, there was an awareness that as women they seemed to deal with particular issues regarding their insecurities as academics, which could be addressed in mentorship with a woman or with all-women groups:

I think that that feeling of being an imposter is something that ... we all share ... especially maybe women carry... it's an all-woman group ... I think that's been quite helpful to kind of help to cut away the nonsense, the things that might be pretence and to put forward the more foundational stuff. [Participant 4]

Literature on academic mentorship has highlighted the complex nature of the relationship, the value of 'having the right chemistry' between mentor and mentee, and that mentorship involves attending to personal as well as academic issues (Jackson Palepu and Szalacha 2003; Sambunjak, Straus and Marusic 2010). Much has also been written about the characteristics of an effective mentor (Bower, Diehr and Morzinksi 1998; Johnson 2002; Quinn and Vorster 2012). In this case study, key enabling factors which emerged with respect to the mentor were her independent location outside the immediate power structures of the mentees, which seemed to be especially important for these staff members engaged in doctoral studies; her experience as a senior academic with experience 
and credibility in conducting and overseeing research; as well as her gender and psychological skills which they felt allowed her to deal with some of the broader challenges facing the mentees as women and researchers.

\section{Mentorship and supervision}

Interestingly, and centrally, much of the feedback and discussion around mentoring speaks to the relationship between mentorship and supervision. Firstly, mentees commented on how the process of mentorship provided focused time to work on their thesis, and seemed to legitimise this endeavour, in the face of the many other demands which academics experience as being priorities. This was something that supervision, which was experienced as being much more embedded in ongoing academic work, did not seem to provide as clearly:

And I think, I think that ja, the, the group ac, the mentorship programme activities are recognised as uh, valid time and involvement. So asking somebody about something isn't, is what you do, it's not can I have five minutes of your time, if not this week then next week? [Participant 8]

Linked to this, participants also indicated that the mentorship role required large amounts of dedicated time from the mentor, which supervisors often did not seem to have:

I don't know one single academic in [name of unit] who actually has time to be a mentor. Everybody is so busy, all the academics. There's not one I know who isn't over-burdened with project work, student work ... teaching load ... teaching, marking. [Participant 10]

Secondly, a key feature of the mentorship valued by participants was that it stood outside of the traditional power relationships, which are inevitably part of the supervisorsupervisee relationship, where the supervisor is commonly a more senior academic colleague, often in the same department or unit as the supervisee. Thus, the fact that the mentor was not affiliated to the faculty in which the project was undertaken meant that she did not wear 'different hats' in her mentorship relationship with participants:

I think it's 'cause we feel like students ... ja ... ja ... I think that's the, the dynamic that we're grappling with. You sort of relate to your supervisor, your thesis supervisor as your lecturer and you're the student. It's very difficult to sort of go, beyond that ... It's a power dynamic. [Participant 9]

Mentees stated that this was also a space where they could discuss more personal issues, which were not appropriate in the supervision relationship:

So I think one of the uniques, or one of the things that I found that is different going to my supervisors or going to [mentor] as a mentor is that there's a lot more kind of personal things that I can talk about with [mentor] or, you know, what my difficulties are in getting down to do the work because of personal things, and things like that which I mean I can say to my 
supervisors but they're not interested, [slight pause], I mustn't say they're not interested because they're very caring people but they are there for the academic, and to assist me with the academic role. [Participant 4]

However, the relationship between mentorship and supervision may also throw up particular challenges. For example, there was the possibility of more junior supervisors feeling somewhat threatened by the research experience of the mentor:

It's also around roles and competencies and I think [mentor]'s playing a role of mentor, but she's actually highly competent, and even more competent than a supervisor in particular skills then it's gonna create a tension ... ja. [Participant 8]

In addition, supervisors were not always clear about the role of the mentor:

The one, the one thing that I find difficult is that I think my supervisors don't really understand where the mentor programme fits in. And there's a lot of, I think they feel a little bit threatened by her role ... you know, what is this relationship and what are the boundaries and ... you know, it's so obvious that I hold her in, you know, high esteem. [Participant 2]

On the one hand, then, there was a sentiment that the roles of supervisor and mentor could not necessarily be clearly demarcated all the time, and that some overlap was inevitable:

So I think that that's something ... about the kind of knowing what, the roles are. But there doesn't even need to be boundaries because there is going to be crossover, so it's not like a boundary this one or that one, there's going to be some kind of crossover ... ja. [Participant 4]

Yet, on the other hand, there was nevertheless the need for greater clarification of the role of the mentor within the faculty, and with supervisors particularly:

I think that speaks to, you know, some sort of process of legitimising the programme in the faculty, and that everybody's supervisor should be made aware of the programme and what the role of the mentor is. Because maybe, I don't think it was introduced to all the supervisors in that way ... mm ... ja. [Participant 10]

Regarding the relationship between mentorship and supervision, in a recent survey on the research experience of young scientists in South Africa, a vast majority (83\%) indicated that they saw the value of having a mentor in addition to a supervisor, and those with at least one mentor were more likely to report good or excellent academic progress compared to those without mentors (Schutte, Wright, Langdon, Lochner and Myers 2013). However, it would seem important for a faculty implementing mentorship of staff to orientate colleagues, and especially those involved in supervision, to the role of mentorship, and to include ongoing monitoring and negotiation of the role of the mentor, as well as training and support for supervisors (Boughey and McKenna 2013). It would also be necessary for the mentor to clarify her position with mentees from the outset, and to be alert 
to areas of possible confusion (Noonan et al. 2007). What also became clear from this study was that, while the supervisor generally needs to have specialist expertise in either the field of study or the methodology to be used, this is not necessarily the case for the mentor, whose role requires rather academic and life experience, as well as research and supervision experience. Thus, the mentor can provide mentorship to a range of mentees across various disciplines (Geber 2010).

\section{Reflections and conclusions}

Generally, it seems clear that participants in this mentorship programme found mentorship to be extremely helpful and to play a strongly positive role in helping them complete their doctoral studies. Positive outcomes of mentorship have also been identified in a variety of other studies (Geber 2010; Johnson 2002; Leidenfrost et al., 2014; Paglis et al. 2006; Schulze 2010; Schrubbe 2004).

However, the findings raise a number of interesting questions for consideration. Firstly, there is the issue of whether the addition of mentorship for doctoral candidates is indeed justified. The reality of academia in South Africa and internationally, with growing student numbers in higher education but without a commensurate growth in academic staff numbers, is that staff generally feel highly pressured by their teaching and grading, administration, and research demands (Quinn and Vorster 2012; Usher 2002). Thus, the addition of supervision responsibilities often means that supervisors are unable to devote the amount and quality of time needed by candidates (Wadesango and Machingambi 2011), a situation to which participants in this mentorship programme were sensitive and sympathetic, and so were at times reluctant to 'impose' on their colleague/supervisor's time. As the staffing situation at universities in South Africa is unlikely to change significantly in the foreseeable future, it is not surprising that there are increasingly attempts to seek alternative models of support/supervision (Bitzer and Albertyn 2011). Thus, the use of senior /retired academics outside of the university mainstream for mentorship is one innovative way to address this problem (Nundulall and Reddy 2011).

In addition, a notable feature of this project was that all the participants were women, including the mentor, and that this was perceived by participants to be strongly enabling. While this was initially the result of the project being located in a women's health research unit, the programme was later extended to include a range of different departments and units within the faculty. Yet, at no stage of the project have any men been participants, despite the programme being open to all academics within the units involved. Thus, the question is raised as to why it was exclusively women who were referred to or took up the offer of mentorship. In this study, it appeared that the pressures of the multiple and gendered roles of doing a $\mathrm{PhD}$, while balancing demands of work and family that women traditionally take on, together with a sense of identification with a female mentor who understood these challenges, contributed to these women academics' valuing of the flexible and supportive framework of mentorship. The issue of gender has also been raised in literature on academic mentorship, typically with arguments for the empowerment of women 
in academia (Mokone et al. 2012; Patton 2009; Wolhuter, Peckham, Van der Watt 2013), and would clearly need to be addressed in future mentoring initiatives.

Another question is when and for which staff conducting doctoral studies mentorship is necessary. While the literature often frames mentorship as a desirable resource for junior/emerging, and within the South African context, staff from previously disadvantaged backgrounds (Clowes and Shefer 2013), arguably mentorship is a key component of any supervision practice (Louw and Muller 2014). Thus, rather than viewing mentorship within a deficit model, mentorship could also be offered more generally to staff who themselves feel that they would benefit from such support, which allows for more collegial, non-hierarchical frameworks for inducting staff and students into a scholarly community of practice.

Finally, a recurring and cross-cutting issue hinged on notions of power, and the many ways in which the traditional supervision relationship entrenches experiences of disempowerment for students (Grant 2003). This was clearly experienced as a challenge for the participants of this study, especially given their location as academic staff members, often supervised by senior colleagues within the same academic unit or department. Thus, mentorship by an independent mentor is clearly one important way to address these issues, allowing for a space that is outside of the authoritarian, 'output-oriented' framework of current practices of supervision.

In conclusion, mentorship with an appropriate mentor, and, importantly, outside of the more traditional academic framework of supervisor-supervisee, is clearly a valuable resource in supporting postgraduate students, especially academic staff with multiple demands on their time and energy, to progress in their studies. Given the South African context of a backlog in postgraduate output, together with over-extended supervisors, and the imperative to graduate competent and capable doctoral candidates economically (both in terms of time and expense), providing mentorship programmes that hinge on established researchers with extensive research and higher education experience seems to offer an important alternative. Moreover, such a framework of mentorship could arguably suggest ways in which all postgraduate supervision should be moving to better support the development of agentic, scholarly identity.

\section{Acknowledgement}

The authors wish to acknowledge the financial and administrative support of the Mellon Retired and Visiting Scholars Mentorship Project and the Research Office at the University of Cape Town for the mentorship project on which this article is based. This manuscript was written and prepared separately from programme participation. The ideas and opinions expressed herein are solely those of the authors. 


\section{References}

Academy of Science of South Africa (ASSAf 2010). The PhD study: An evidence-based study on how to meet the demands for high-level skills in an emerging economy. Pretoria: ASSAf

Badat, S. 2007. Higher education transformation in South Africa post 1994: Towards a critical assessment. Johannesburg: CEPD.

Bitzer, E. M. and R. M. Albertyn. 2011. Alternative approaches to postgraduate supervision: A planning tool to facilitate supervisory processes. South African Journal of Higher Education 25(5): 874-888.

Boughey, C. and S. McKenna. 2013. Enhancing doctoral supervision in a diverse higher education system. International Association of Universities Horizons 19(2): 26-27.

Bower, D., S. Diehr, J. A. Morzinski and D. E. Simpson. 1998. Support-challenge-vision: A model for faculty mentoring. Medical Teacher 20(6): 595-597.

Cloete, N. and I. Bunting. 2013. Challenges and opportunities for African Universities to increase knowledge production. Programme on Innovation, Higher Education and Research for Development. Available at http://www.chet.org.za/papers/challengesand-opportunities-african-universities-increase-knowledge-production (accessed 22 March, 2014).

Clowes, L. and T. Shefer. 2013. 'It's not a simple thing, co-publishing': The politics of coauthorship between supervisors and students in South African higher educational contexts. Africa Education Review 10(1): 32-47.

Clutterbuck, D. and G. Lane. 2004. The situational mentor: An international review of competencies and capabilities in mentoring. Burlington / Hant: Gower.

Council on Higher Education (CHE) and Centre for Research on Science and Technology (CREST) 2009. Postgraduate studies in South Africa: a statistical profile. Higher Education Monitor 7. Pretoria: Council on Higher Education.

Eby, L., J. Rhodes and T. Allen. 2007. Definition and evolution of mentoring. In The Blackwell Handbook of mentoring: A multiple perspective approach ed. T. Allen and L. Eby, 7-20. Oxford: Blackwell.

Geber, H. 2010. Coaching for accelerated research productivity in higher education. International Journal of Evidence Based Coaching and Mentoring 8(2): 64-78.

Geber, H. and A. Bentley. 2012. Can low-cost support programmes with coaching accelerate doctoral completion in Health Science Faculty academics? Perspectives in Education 30(3): 30-38.

Govender, K. and R. Dhunpath. 2011. Student experiences of the PhD cohort model: Working within or outside of communities of practice? Perspectives in Education 29(3): 88-99.

Grant, B. 2003. Mapping the pleasures and risks of supervision. Discourse: Studies in the Cultural Politics of Education 24(2): 175-190.

Jackson, V., A. Palepu, L. Szalacha, C. Caswell, P. Carr and T. Inui. 2003. 'Having the right chemistry': A qualitative study of mentoring in academic medicine. Academic Medicine 78(3): 328-334.

Johnson, W. B. 2002. The intentional mentor: Strategies and guidelines for the practice of mentoring. Professional Psychology: Research and Practice 33(1): 88-96. 
Kamler, B. and P. Thomson. 2006. Helping doctoral students write: pedagogies for supervision. London and New York: Routledge.

Leidenfrost, B., B. Strassnig, M. Schutz, C. Carbon and A. Schabmann. 2014. The impact of peer mentoring on mentee academic performance: Is any mentoring style better than no mentoring at all? International Journal of Teaching and Learning in Higher Education 26(1): 102-111.

Louw, J. and J. Muller. 2014. A literature review on models of the PhD. Johannesburg: Centre for Higher Education Transformation.

Mokone, M., R. Malema, R. Maphanga, M. Tlowane, N. Lesolang, M. Rapetsoa and E. Ramani. 2012. This journey never ends! The University of Limpopo Women's Academic Solidarity Association experience. Agenda: Empowering women for gender equity 26(4): 140-151.

Mouton, J. 2011. Doctoral production in South Africa: Statistics, challenges and responses. Perspectives in Education 29(3): 13-29.

Mullen, C. A., V. L. Fish and J.L. Hutinger. 2010. Mentoring doctoral students through scholastic engagement: Adult learning principles in action. Journal of Further and Higher Education 34(2): 179-197.

Noonan, M. J., R. Ballinger and R. Black. 2007. Peer and faculty mentoring in doctoral education: Definitions, experiences and expectations. International Journal of Teaching and Learning in Higher Education 19(3): 251-262.

Nundulall, R. and N. Dorasamy. 2012. Mentorship and sustainable research output: A case study of the University of Johannesburg. Industry and Higher Education 26(2): 127137.

Nundulall, R. and K. Reddy. 2011. Mentorship as a strategy to improve research output at tertiary institutions: A case study of University of Johannesburg. South African Journal of Higher Education 25(6):1155-1177.

Paglis, L., S. Green and T. Bauer. 2006. Does advisor mentoring add value: A longitudinal study of mentoring and doctoral student outcomes. Research in Higher Education 47(4): 451-476.

Patton, L. 2009. My sister's keeper: A qualitative examination of mentoring experiences among African American women in graduate and professional schools. Journal of Higher Education 80(5): 510-537.

Pillay, P. 2010. Linking higher education and development. Cape Town: Centre for Higher Education Transformation.

Quinn, L. and J. Vorster. 2012. Training new academics is a complex challenge. A supplement to the Mail \& Guardian Oct $5-112-3$.

Sambunjak, D. D., S. Straus and A. Marusic. 2010. A systematic review of qualitative research on the meaning and characteristics of mentoring in academic medicine. Journal of General Internal Medicine 25(1): 72-78.

Schrubbe, K. 2004. Mentorship: A critical component for professional growth and academic success. Journal of Dental Education 68(3): 324-328.

Schulze, S. 2010. Mentees' views of a structured mentoring programme at Unisa. South African Journal of Higher Education 24(5): 782-799. 
Schutte, A.E., C.Y. Wright, G. Langdon, C. Lochner and B. Myers. 2013. What is the research experience of young scientists in South Africa? South African Journal of Science 109(11/12).

Usher, R. 2002. A diversity of doctorates: Fitness for the knowledge economy? Higher Education Research and Development 21(2): 143-153.

Wadesango, N. and S. Machingambi. 2011. Post-graduate students' experiences with research supervisors. Journal of Sociology and Social Anthropology 2(1): 31-37.

Wolhuter, C., G. Peckham, J.L. van der Watt and F.J. Potgieter. 2013. The research output of female academics at a South African university: Progress and gender equity. Africa Education Review 10(1): 148-166. 